\title{
An audit of high dose-rate prostate brachytherapy treatment planning at six Swedish clinics
}

\author{
Frida Dohlmar, MSc', Sakarias Johansson, RN, MSc², Torbjörn Larsson, Prof.3., Michael Sandborg, Ass. Prof.,4, \\ Åsa Carlsson Tedgren, Ass. Prof., 1,4,6 \\ 'Medical Radiation Physics, Department of Health, Medicine and Caring Sciences, Linköping University, Linköping, Sweden, ${ }^{2}$ Department of \\ Oncology, Karolinska University Hospital, Stockholm, Sweden, ${ }^{3}$ Department of Mathematics, Linköping University, Linköping, Sweden, ${ }^{4}$ Center \\ for Medical Image Science and Visualization, CMIV. Linköping University, Linköping, Sweden, ${ }^{5}$ Department of Medical Radiation Physics and \\ Nuclear Medicine, Karolinska University Hospital, Stockholm, Sweden, ${ }^{6}$ Department of Oncology Pathology, Karolinska Institute, Stockholm. \\ Sweden
}

\begin{abstract}
Purpose: High dose-rate prostate brachytherapy has been implemented in Sweden in the late 1980s and early 1990s in six clinics using the same schedule: 20 Gy in two fractions combined with 50 Gy in 25 fractions with external beam radiation therapy. Thirty years have passed and during these years, various aspects of the treatment process have developed, such as ultrasound-guided imaging and treatment planning system. An audit was conducted, including a questionnaire and treatment planning, which aimed to gather knowledge about treatment planning methods in Swedish clinics.

Material and methods: A questionnaire and a treatment planning case (non-anatomical images) were sent to six Swedish clinics, in which high-dose-rate prostate brachytherapy is performed. Treatment plans were compared using dosimetric indices and equivalent $2 \mathrm{~Gy}$ doses $\left(\mathrm{EQD}_{2}\right)$. Treatment planning system report was used to compare dwell positions and dwell times.

Results: For all the clinics, the planning aim for the target was $10.0 \mathrm{~Gy}$, but the volume to receive the dose differed from $95 \%$ to $100 \%$. Dose constraints for organs at risk varied with up to $2 \mathrm{~Gy}$. The dose to $90 \%$ of target volume ranged from 10.0 Gy to $11.1 \mathrm{~Gy}$, equivalent to 26.0 Gy $\mathrm{EQD}_{2}$ and $31.3 \mathrm{~Gy} \mathrm{EQD}_{2}$, respectively. Dose non-homogeneity ratio differed from 0.18 to 0.32 for clinical target volume (CTV) in treatment plans and conformity index ranged from 0.52 to 0.59 for CTV.

Conclusions: Dose constraints for the organs at risk are showing a larger variation than that reflected in compared treatments plans. In all treatment plans in our audit, at least $10 \mathrm{~Gy}$ was administered giving a total treatment of $102 \mathrm{~Gy} \mathrm{EQD}_{2}$, which is in the upper part of the prescription doses published in the GEC/ESTRO recommendations.

J Contemp Brachytherapy 2021; 13, 1: 59-71 DOI: https://doi.org/10.5114/jcb.2021.103588
\end{abstract}

Key words: brachytherapy, audit, dosimetric indices.

\section{Purpose}

High dose-rate (HDR) brachytherapy (BT) has been a part of standard care of prostate cancer in Sweden since the late 1980s and early 1990s [1,2,3,4]. The technique was described by Borghede et al. [1], with a prescription dose of $20 \mathrm{~Gy}$ in two fractions (fx) using iridium-192 $\left({ }^{192} \mathrm{Ir}\right)$ combined with external beam radiation therapy (EBRT) of $50 \mathrm{~Gy}$ in $25 \mathrm{fx}$. The national care programme [5] still recommends the same fractionation schedule, which is currently the only combined EBRT and BT fractionation scheme recommended. The national care program does not include recommendation on how to perform the irradiation or which doses to accept for the organs at risk (OARs), neither to which volume the prescribed dose should be given. The early treatment results have been published, with various data of the method used for treatment planning. Table 1 presents a summary of planning aims and dose restrictions used $[1,2,3,4,6,7]$.

In the beginning of prostate HDR-BT, all treatment plans have been created using forward treatment planning $[8,9]$. As treatment planning systems (TPSs) improved, inverse treatment planning [10] became available $[11,12]$. The early inverse planning algorithms implemented in TPSs were not producing acceptable treatment plans, and manual and/or graphical adjustments were therefore needed $[13,14]$. Manual adjustments were due to uneven distributions of dwell times, which made the dose distribution more uneven, with larger high- and low-dose regions, so-called "hot" and "cold spots", com- 
Table 1. Published Swedish planning technique data; where no data are presented, the article does not state the data

\begin{tabular}{|c|c|c|c|c|c|c|}
\hline Volume & $\begin{array}{l}\text { Borghede } \\
(1997)[1] \\
\end{array}$ & $\begin{array}{l}\text { Borghede } \\
(1997)[6] \\
\end{array}$ & $\begin{array}{l}\text { Åström } \\
(2005)[2]\end{array}$ & $\begin{array}{l}\text { Kälkner } \\
(2007)[3]\end{array}$ & $\begin{array}{l}\text { Lennernäs } \\
(2015)[7]\end{array}$ & $\begin{array}{l}\text { Åström } \\
(2018)[4]\end{array}$ \\
\hline Target & $D_{\min }=10 G y$ & $\begin{array}{c}D_{\min }=10 \mathrm{~Gy} \\
15 \text { Gy to the tumor }\end{array}$ & $\begin{array}{c}\text { CTV covered } \\
\text { with } 10 \mathrm{~Gy} \\
\text { isodose }\end{array}$ & 10 Gy to PTV & $D_{\min }=10 G y$ & $\begin{array}{l}\text { PTV encom- } \\
\text { passed by the } \\
10 \text { Gy isodose }\end{array}$ \\
\hline Margin & $2 \mathrm{~mm}$ & $2 \mathrm{~mm}$ & $2 \mathrm{~mm}$ & $3 \mathrm{~mm}$ & $3 \mathrm{~mm}$ & $2 \mathrm{~mm}$ \\
\hline $\begin{array}{l}\text { Number of } \\
\text { catheters }\end{array}$ & $6-15$ & - & $6-21$ & $10-18$ & - & $10-22$ \\
\hline Urethra & 8-9 Gy & $<8 \mathrm{~Gy}$ & - & - & - & $\begin{array}{l}\text { 1995-1999: } \\
\text { None } \\
\text { 2000-2008: } \\
\text { < } 12 \text { Gy }\end{array}$ \\
\hline Rectum & $<6 \mathrm{~Gy}$ & - & - & $<6 \mathrm{~Gy}$ & $<6 \mathrm{~Gy}$ & $\begin{array}{l}\text { 1995-1999: } \\
\text { None } \\
\text { 2000-2005: } \\
\text { < 6.5 Gy } \\
\text { 2006-2008: } \\
\text { < } 5 \text { Gy }\end{array}$ \\
\hline Data collected & - & 1988-1994 & $1988-2000$ & 1998-1999 & $1996-2001$ & $1995-2008$ \\
\hline
\end{tabular}

pared with manual treatment planning. Even a decade later, clinically available inverse planning algorithms often produced treatment plans that needed adjustments to achieve acceptable target coverage and OARs doses [15]. However, the inverse planning algorithms could decrease the planning time and make the process less dependent on skills of individual treatment planners [16].

There are international recommendations and guidelines on HDR prostate BT, such as the Groupe Européen de Curiethérapie (GEC) and the European Society for Radiotherapy and Oncology (ESTRO) recommendations [17], and the American Brachytherapy Society (ABS) guidelines [18]. Though the articles $[17,18]$ have presented various examples of used fractionation schedules, there is still no recommendation that can be utilized. GEC/ ESTRO have proposed some OARs constraints (Table 2), which apply for the whole treatment regime, and include only HDR-BT or both HDR-BT and EBRT. The reported dose to target should be the dose to $90 \%$ of the target, which may be the clinical target volume (CTV) or the planning target volume (PTV), which here is denoted as $\mathrm{D}_{90 \%}^{\text {CTV }}$ or $\mathrm{D}_{90 \%}^{\text {PTV }}$. Treatment planning methods are mentioned in the GEC/ESTRO and ABS recommendations. GEC/ESTRO state that the treatment planning "can be

Table 2. Organs at risk constraints proposed in the GEC/ESTRO recommendations and the proposed constraints for the BT part of the treatment, if $50 \mathrm{~Gy}$ is received from EBRT

\begin{tabular}{|c|c|c|}
\hline Organ & $\begin{array}{c}\text { Constraints whole } \\
\text { treatment }\end{array}$ & $\begin{array}{l}\text { Constraints HDR-BT, } \\
\text { if } 50 \text { Gy EBRT }\end{array}$ \\
\hline Rectum & $\mathrm{D}_{2 \mathrm{cc}} \leq 75$ Gy EQD & $D_{2 c c} \leq 6.5 \mathrm{~Gy}$ \\
\hline Urethra & $\begin{array}{l}D_{0.1 c c} \leq 120 \text { Gy EQD } \\
D_{10 \%} \leq 120 \text { Gy EQD } \\
D_{30 \%} \leq 105 \text { Gy EQD }\end{array}$ & $\begin{array}{l}\mathrm{D}_{0.1 \mathrm{cc}} \leq 11.8 \mathrm{~Gy} \\
\mathrm{D}_{10 \%} \leq 11.8 \mathrm{~Gy} \\
\mathrm{D}_{30 \%} \leq 10.3 \mathrm{~Gy}\end{array}$ \\
\hline
\end{tabular}

carried out by conventional or inverse planning", where "conventional" apply for manual and graphical optimization. The ABS propose that "a computerized optimization program based on geometric or inverse planning algorithm should be used, although manual optimization is also acceptable".

In Sweden, HDR-BT for prostate cancer was introduced thirty years ago, and the equipment used, such as ultrasound (US) imaging and TPS, has developed over the years. Six clinics implemented the technique described by Borghede et al. [1]. Clinical experiences have obviously affected clinical routines in the HDR-BT treatment of prostate cancer, such as margins for treatment, planning aims for target coverage, and sparing of OARs. Furthermore, these aspects of practical routines could have been modified differently at different clinics since their implementation. The experience gained at different clinics might also affect the number of catheters used and the routine for placement of the catheters.

An audit of treatment plans may highlight the differences in clinical routines. A clinical audit is a process aiming to improve the patient outcome through a systematic review with explicit criteria. Such an audit is an important instrument for quality assurance in radiotherapy, which can be used as a tool to understand what different clinics are able to achieve with their equipment and methods [19].

The aim of this work was to analyze the dose constraints and planning aims at Swedish clinics, and to assess how these are affecting treatment plans. Treatment plans were evaluated by using dosimetric indices (DI) recommended in the GEC/ESTRO and ABS guidelines $[17,18]$. We also compared some additional parameters that may highlight differences and similarities of the treatment plans, such as 2 Gy equivalent dose $\left(\mathrm{EQD}_{2}\right)$ and mean doses of $5 \%$ and $1 \%$ coldest regions in the target volume. It was conducted under the premise that 
the same delineation of prostate (CTV), urethra, and rectum was used to isolate the comparison to the treatment planning process. Our audit was organised to assess the treatment planning process at the six Swedish clinics that perform HDR BT prostate treatments to gain knowledge of how the treatment plans are affected by the routines used today. It was set up as a questionnaire and a phantom HDR BT prostate case.

\section{Material and methods}

\section{Questionnaire}

A questionnaire was sent to six Swedish clinics, here represented by letters from $\mathrm{A}$ to $\mathrm{F}$. The questionnaire included ten questions about clinical routine and equipment used (Table 3). In addition, the clinics were asked to produce a treatment plan for a phantom prostate patient.

\section{Treatment planning}

A phantom study was performed employing ultrasound (US) images without any anatomical information, using Vitesse planning system version 2.5 (Varian Medical Systems Inc., Palo Alto, USA), and including markers to visualize possible positions in the catheter template. A clinical CTV $\left(21.5 \mathrm{~cm}^{3}\right)$ and sensitive organs (urethra and rectum) were taken from a previously treated patient. The contours were pasted onto the phantom images in BrachyVision version 13.6 (Varian Medical Systems Inc., Palo Alto, USA). An example of US slice with contoured structures is shown in Figure 1. The study was exported in DICOM-format and sent to the six Swedish clinics with instructions. The instructions for the treatment planning were to import the phantom study into the clinical TPS in use, and to perform treatment planning following their own clinical routine. The prescribed dose to the target volume was $10 \mathrm{~Gy}$ in one fraction. The target volume is often CTV (which here is the prostate without seminal vesicles), with a margin named as PTV. The PTV,

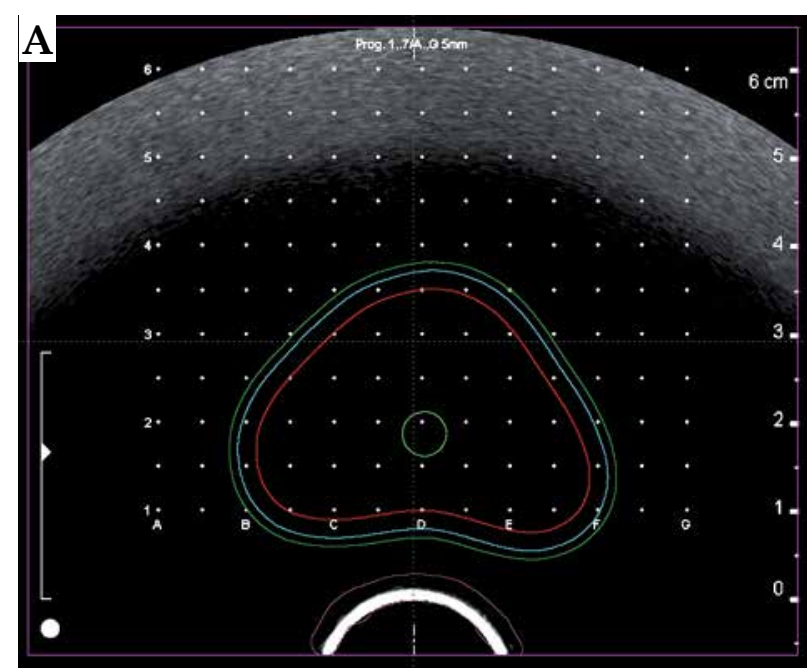

Table 3. The questionnaire with 10 questions sent to the clinics

\begin{tabular}{lc} 
& \multicolumn{2}{c}{ Question } \\
\hline 1. & Which TPS do you use in your clinic? \\
\hline 2. & Which type of radiation source do you use? \\
\hline 3. & Which CTV to PTV margin do you apply (if you are using \\
PTV)?
\end{tabular}

if used, was contoured by the clinic, which means that the PTVs used in the clinics could be of different sizes. When the treatment plan was ready, it was exported and sent back with a report from the TPS, where each catheter and dwell time were presented.

Two clinics (A and B) also produced a second treatment plan on another set of CTV $\left(36.1 \mathrm{~cm}^{3}\right)$ and sensitive organs from a previously treated patient, following the above-mentioned method.

The treatment plans made by clinic $B$ were recalculated using different dose voxel sizes in $\mathrm{x}$ and $\mathrm{y}$ directions; $0.05 \mathrm{~cm}, 0.1 \mathrm{~cm}$, and $0.25 \mathrm{~cm}$. In the $\mathrm{z}$ direction, the dose voxel size was set to the same as the slice thickness of $0.1 \mathrm{~cm}$.

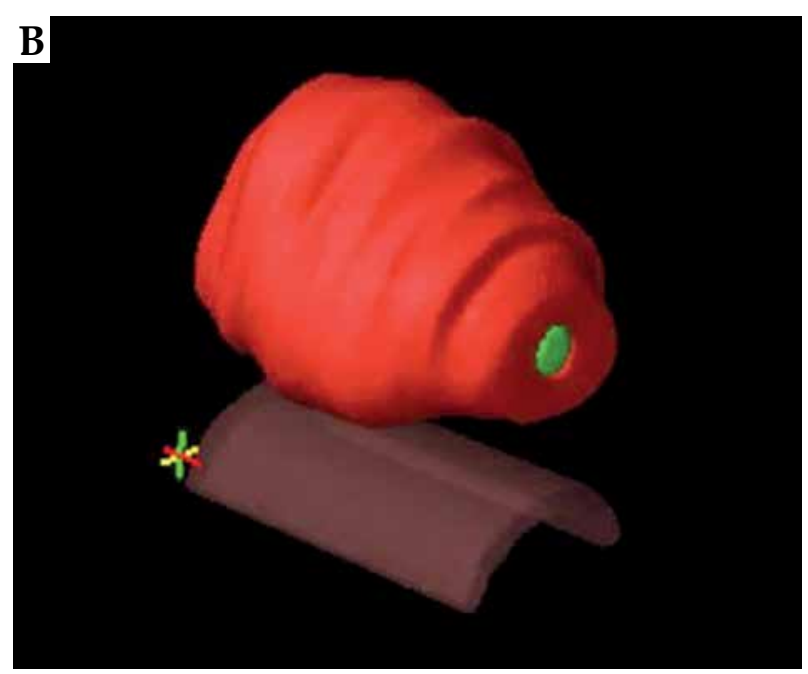

Fig. 1. Ultrasound images from the phantom study sent out in the audit; A) one slice, B) a 3D projection. The contours representing CTV (red), PTV with $2 \mathrm{~mm}$ margin (light blue), PTV with $3 \mathrm{~mm}$ margin (dark green), urethra (light green), rectum (brown), and the whole dose matrix (magenta). Only CTV, urethra, and rectum were sent to the clinics, the other volumes were used for the comparison 


\section{Dosimetric indices}

Dosimetric indices (DIs) were collected from dose-volume histograms (DVHs), using BrachyVision for all treatment plans, where information for contoured volumes were displayed. Therefore, volumes were created in BrachyVision. Two different PTVs, $\mathrm{PTV}_{2 \mathrm{~mm}}$ and $\mathrm{PTV}_{3 \mathrm{~mm}}$ were contoured, representing the most frequently used margins with $2 \mathrm{~mm}$ and $3 \mathrm{~mm}$ margins, respectively, in anterior-posterior direction and lateral direction, and no margin in cranio-caudal direction (Figure 1). A volume for the entire image volume was also created.

DIs were collected manually using the crosshair tool in BrachyVision. The DIs used in the audit, as proposed by the GEC/ESTRO, were for target volumes (CTV, $\mathrm{PTV}_{2 \mathrm{~mm}}$ and $\mathrm{PTV}_{3 \mathrm{~mm}}$ ): the dose that $90 \%$ and $95 \%$ of the volume receives $\left(\mathrm{D}_{90 \%}\right.$ and $\left.\mathrm{D}_{95 \%}\right)$ and the volumes that receive at least $100 \%, 150 \%$, and $200 \%$ of the prescription dose $\left(\mathrm{V}_{100 \%}, \mathrm{~V}_{150 \%}\right.$, and $\left.\mathrm{V}_{200 \%}\right)$. For rectum, the dose that the hottest $2 \mathrm{~cm}^{3}$ receives $\left(D_{2 c c}\right)$ was used, and for urethra, the dose that the hottest $0.1 \mathrm{~cm}^{3}, 10 \%$, and $30 \%$ of the volume receive $\left(\mathrm{D}_{0.1 \mathrm{cc}}, \mathrm{D}_{10 \%}\right.$, and $\left.\mathrm{D}_{30 \%}\right)$ was used. To be able to compare biological doses given, the $\mathrm{EQD}_{2}$ [20] was used and computed as:

$$
E Q D_{2}=D \frac{d+\alpha / \beta}{2+\alpha / \beta}
$$

where $D$ is the total dose, $d$ is the dose per fraction, and $\alpha / \beta$ is the tissue-specific linear-quadratic parameter of the volume. For for prostate, we assumed a value of 3 , as this value is stated in the Swedish National Care Programme [5] and for OARs, a value of 3 was also used.

For CTV, PTV $2 \mathrm{~mm}$, and $\mathrm{PTV}_{3 \mathrm{~mm}}$, dose non-homogeneity ratio (DNR) [21] and conformal index (COIN) [22] were calculated, see equations 2 and 3 below.

$$
D N R=\frac{V_{150}}{V_{100}}
$$

where $\mathrm{V}_{150}$ is the volume of PTV (or CTV) that is enclosed by $150 \%$ of the prescription dose, and $V_{100}$ is the volume of PTV (or CTV) that is enclosed by the prescription dose. A low value of DNR represents a homogenous treatment plan.

Here,

$$
\mathrm{COIN}=c_{1} \times c_{2}
$$

$$
c_{1}=\frac{P T V_{r e f}}{P T V}
$$

and

$$
c_{2}=\frac{P T V_{r e f}}{V_{r e f}},
$$

where PTV is the volume of PTV (or CTV), PTV ref is the volume of PTV (or CTV) that is enclosed by the prescription dose $\left(D_{r e f}\right)$, and $V_{\text {ref }}$ is the total volume enclosed by the reference isodose, i.e., the prescription isodose. The ideal would be if both $c_{1}$ and $c_{2}$ had a value of 1 , where $c_{1}$ and $c_{2}$ define how well $D_{\text {ref }}$ covers PTV; in addition, $c_{2}$ describes how much of the normal tissue was irradiated by the prescription dose.

The mean dose to the coldest volume (lower conditional value-at-risk - LCVaR) [23] in radiation therapy is referred to as mean-tail dose, which is a measure of how low the dose is for the coldest part of target volume. An LCVaR near the prescription dose demonstrates a treatment plan, which does not have any unwanted underdosage. LCVaR is calculated as:

$$
\operatorname{LCVaR}_{\alpha}^{s}=\frac{1}{\alpha\left|P_{S}\right|} \sum_{i \in P_{S}: D_{o s e_{i}} \geq D_{1-\alpha}^{s}} \text { Dose }_{i}
$$

where $\alpha$ is the percentage of the structure $S$, for which the $L C V a R_{\alpha}^{s}$ is calculated. Here, $\alpha$ is $5 \%$ or $1 \%$, and $S$ is $\mathrm{PTV}_{2 \mathrm{~mm}}, \mathrm{PTV}_{3 \mathrm{~mm}}$, or CTV.

\section{Analysis of the treatment plan reports}

The dwell time pattern was compared using TPS reports from the clinics. The dwell times were compared using nominal times based on a source strength of $40.7 \mathrm{mGy} / \mathrm{h}$, which corresponds to an activity of $370 \mathrm{GBq}$. Several clinics are planning treatments based on the actual source strength; here, these values were adjusted to $40.7 \mathrm{mGy} / \mathrm{h}$ for comparison. In the reports, number of catheters and number of source positions were listed, including every dwell time for the treatment plan and placement of dwell positions in relation to the tip of catheter. The dwell time positioning pattern was described using a definition of Yoshioka et al. [24]. Cylindrical dwell position (CDP) is when in all catheters, the same offset to the catheter tip is used; anatomy-based dwell position (ABDP) is when the offset for the first dwell position from the catheter tip is decided based on the distance to the prostate contour (Figure 2). Total reference air kerma (TRAK) [25] was also included in the reports from the treatment plans and used for the comparison. Moreover, linear regression was applied to estimate relations between different dependent parameters (i.e., number of catheters, TRAK, total treatment time, target coverage, high-dose areas, and OARs doses) and independent variables (dose or relative volume).

\section{Uncertainty analysis}

The BT treatment process includes a series of steps, all of which are related to some uncertainty [26]. In Kirisits et al. [27], an example of uncertainty analysis for HDR-BT treatment of the prostate using US images has been published. Our audit compared DIs from the treatment plans; therefore here, the uncertainty should be less than the total of $5 \%(k=1)$ that Kirisits states. According to Van der Meer et al. [28], the number of dose points to achieve DIs with a confidence interval of $95 \%$ is 32,000 points for the target and 256,000 points for every organ at risk. The commercial TPSs have different settings for the structures, such as how the interpolation of structures and the inclusion or exclusion of intersecting structures, such as urethra for prostate, are performed. The use of one TPS to derive the DIs excludes these types of uncertainty.

\section{Results}

The results were provided from all six clinics in Sweden, where HDR-BT is performed for the treatment of prostate cancer. For the treatment planning part of the audit, one clinic (F) had some technical problems with 
A

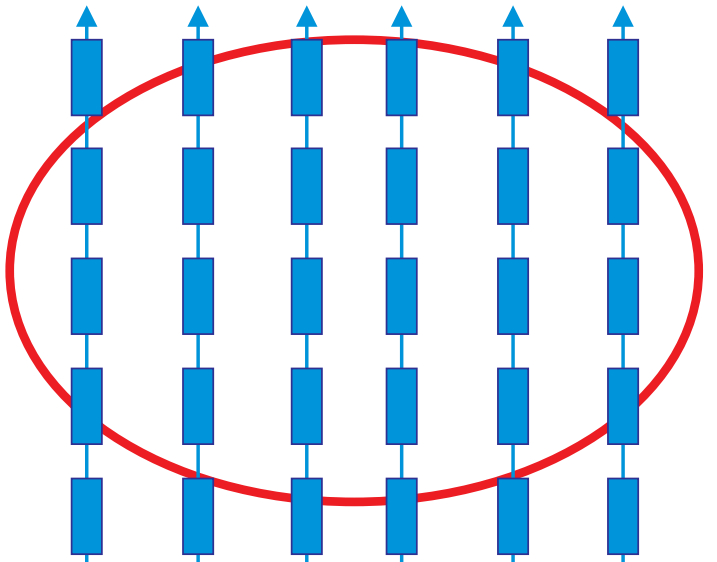

B

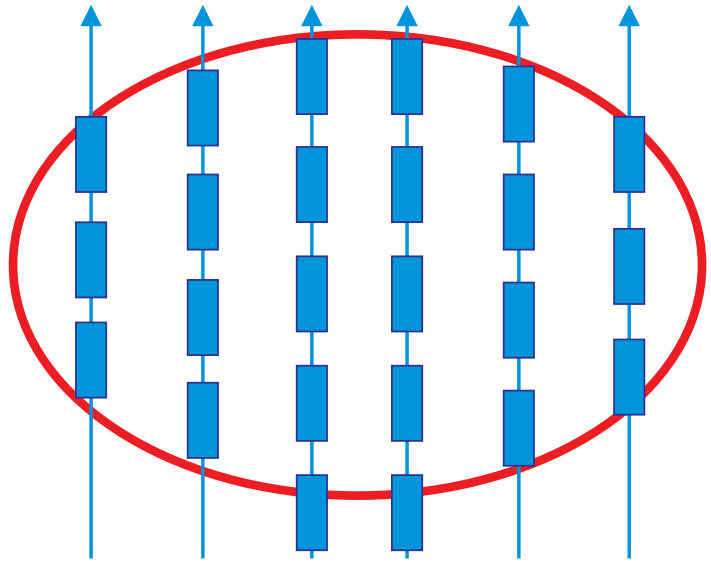

Fig. 2. Schematic figure to illustrate the difference between A) cylindrical dwell position and B) anatomy-based dwell position. The ellipse represents the target volume, the arrows are the catheters and the rectangles are the dwell positions

data transfer, and data from this clinic were not included in the treatment planning part. A clinic that uses Vitesse could not import the study and chose to plan the treatment in BrachyVision to be able to participate in the audit. One clinic (B) changed their planning aims during the audit. This clinic provided two answers to the questionnaire, where applicable, and two treatment plans, where the old method was denoted as B1 and the new technique as B2.

\section{Questionnaire}

The planning aims and dose constraints for the clinics are presented in Table 4 . The planning aims for the target were 10.0 Gy for all the clinics, but the volume to receive the dose differed from $95 \%$ to $100 \%$, while the dose constraints varied up to $2 \mathrm{~Gy}$ for OARs.
Responses to short-answer questions of the questionnaire are listed in Table 5. There were only two vendors in the clinics: BrachyVision and Oncentra Prostate (Elekta Instrument AB Stockholm, Sweden). The clinics with BrachyVision were using a dwell step size of $5 \mathrm{~mm}$, and the clinics with Oncentra Prostate were employing $2.5 \mathrm{~mm}$. The Oncentra Prostate clinics were using a dose voxel size of $0.1 \mathrm{~mm}$ in all three dimensions, while the voxel size varied for the BrachyVision clinics. All clinics were using a slice thickness of $0.1 \mathrm{~mm}$ as the voxel size in the $\mathrm{z}$ direction. The voxel sizes in $\mathrm{x}$ and $\mathrm{y}$ directions varied from $0.25 \mathrm{~mm}$ to $0.05 \mathrm{~mm}$. These variations resulted in a difference of the number of dose voxels for the volumes. The number of voxels for the target volume ranged from approximately 3,300 to 82,800 . For rectum, the number of dose voxels varied from approximately 500 to 13,200 , and for urethra from approximately 100 to 2,800 .

Table 4. Planning aims and dose constraints for the six clinics, the clinics are denoted as letters from $A$ to $F$. Clinic B changed methods during the audit and provided two answers: B1, the old method and B2, the new method

\begin{tabular}{|c|c|c|c|c|c|c|c|}
\hline Volume & $A$ & B1 & B2 & $C$ & $D$ & E & $\mathrm{F}$ \\
\hline \multirow[t]{4}{*}{ PTV } & $D_{100 \%}=10$ Gy & $D_{\min }=10 G y$ & $D_{\min }=10 \mathrm{~Gy}$ & $V_{100 \%}>95 \%$ & $V_{100 \%}>95 \%$ & $V_{100 \%}>95 \%$ & \\
\hline & & & & $V_{150 \%}<55 \%$ & & $V_{120 \%}<70-75 \%$ & \\
\hline & & & & & & $V_{150 \%}<30-35 \%$ & \\
\hline & & & & & & $\mathrm{D}_{90 \%}>9.5 \mathrm{~Gy}$ & \\
\hline \multirow[t]{2}{*}{ CTV } & - & - & - & $\mathrm{D}_{90 \%}>100 \%$ & - & - & $V_{100 \%}>97 \%$ \\
\hline & & & & & & & $D_{100 \%}>90 \%$ \\
\hline \multirow[t]{2}{*}{ Urethra } & $\mathrm{D}_{\max }<12 \mathrm{~Gy}$ & $\mathrm{D}_{\max }<10 \mathrm{~Gy}$ & $\mathrm{D}_{\text {mean }} \leq 11 \mathrm{~Gy}$ & $\mathrm{D}_{\max }<120 \%$ & $\mathrm{D}_{\max }<11 \mathrm{~Gy}$ & $\mathrm{D}_{\max }<12 \mathrm{~Gy}$ & $\mathrm{D}_{\max }<110 \%$ \\
\hline & & & $\mathrm{D}_{\max }<11.5 \mathrm{~Gy}$ & & & $\mathrm{D}_{0.1 \mathrm{cc}}<11.4 \mathrm{~Gy}$ & \\
\hline \multirow[t]{2}{*}{ Rectum } & $\mathrm{D}_{2 \mathrm{cc}}<7.5 \mathrm{~Gy}$ & $D_{\max }<6$ Gy & $D_{\max }<6$ Gy & $\mathrm{D}_{\max }<80 \%$ & $\mathrm{D}_{\max }<7 \mathrm{~Gy}$ & $\mathrm{D}_{\max }<8 \mathrm{~Gy}$ & $D_{10 \%}<65 \%$ \\
\hline & & & & $D_{2 c c}<60 \%$ & & $\mathrm{D}_{2 c c}<5.5 \mathrm{~Gy}$ & \\
\hline \multirow[t]{2}{*}{ Bladder } & - & - & - & - & - & $\mathrm{D}_{\max }<7.5 \mathrm{~Gy}$ & - \\
\hline & & & & & & $\mathrm{D}_{2 c c}<5 \mathrm{~Gy}$ & \\
\hline
\end{tabular}


Table 5. Answers to questions in the questionnaire. Numbers in brackets correspond to question numbers in Table 3. The six clinics are denoted from A to $F$

\begin{tabular}{|c|c|c|c|c|c|c|}
\hline Question & A & $\mathrm{B}$ & $\mathrm{C}$ & $\mathrm{D}$ & $\mathrm{E}$ & $\mathrm{F}$ \\
\hline TPS (1) & $\begin{array}{c}\text { BrachyVision } \\
13.6\end{array}$ & $\begin{array}{c}\text { BrachyVision } \\
13.6\end{array}$ & $\begin{array}{c}\text { BrachyVision } \\
13.6\end{array}$ & $\begin{array}{c}\text { BrachyVision } \\
13.6\end{array}$ & $\begin{array}{c}\text { Oncentra } \\
\text { Prostate } 4.2 .2 .4\end{array}$ & $\begin{array}{l}\text { Oncentra } \\
\text { Prostate }\end{array}$ \\
\hline $\begin{array}{l}\text { Radiation source } \\
\text { (2) }\end{array}$ & $\begin{array}{c}\text { MicroSelectron } \\
\text { V2 }\end{array}$ & $\begin{array}{l}\text { GammaMed } \\
\text { plus HDR }\end{array}$ & $\begin{array}{c}\text { GammaMed } \\
\text { HDR }\end{array}$ & VariSource & $\begin{array}{c}\text { MicroSelectron } \\
\text { V2 }\end{array}$ & $\begin{array}{c}\text { MicroSelectron } \\
\text { V2 }\end{array}$ \\
\hline $\begin{array}{l}\text { CTV to PTV } \\
\text { margin (3) }\end{array}$ & $\begin{array}{c}2 \mathrm{~mm} \text { lateral } \\
\text { and anterior- } \\
\text { posterior }\end{array}$ & $\begin{array}{c}3 \mathrm{~mm} \text { lateral and } \\
\text { anterior- } \\
\text { posterior }\end{array}$ & $\begin{array}{c}2 \mathrm{~mm} \text { lateral } \\
\text { and anterior- } \\
\text { posterior }\end{array}$ & $\begin{array}{c}3 \mathrm{~mm} \text { lateral and } \\
\text { anterior- } \\
\text { posterior }\end{array}$ & $\begin{array}{l}2 \mathrm{~mm} \text { posterior, } \\
\text { lateral, superior } \\
\text { and inferior; } \\
1.5 \mathrm{~mm} \text { anterior }\end{array}$ & No PTV use \\
\hline $\begin{array}{l}\text { Number } \\
\text { of catheters (4) }\end{array}$ & 17 & 15 & 14 & 17 & 16 & 18 \\
\hline $\begin{array}{l}\text { Dose planning } \\
\text { method }(5 A)\end{array}$ & $\begin{array}{l}\text { Inverse, graphi- } \\
\text { cal and manual }\end{array}$ & Inverse & $\begin{array}{l}\text { Inverse and } \\
\text { graphical }\end{array}$ & $\begin{array}{c}\text { Manual and } \\
\text { graphical }\end{array}$ & $\begin{array}{l}\text { Inverse and } \\
\text { graphical }\end{array}$ & $\begin{array}{l}\text { Inverse and } \\
\text { graphical }\end{array}$ \\
\hline $\begin{array}{l}\text { Distance } \\
\text { between source } \\
\text { positions (6A) }\end{array}$ & $5 \mathrm{~mm}$ & $5 \mathrm{~mm}$ & $5 \mathrm{~mm}$ & $5 \mathrm{~mm}$ & $2.5 \mathrm{~mm}$ & $2.5 \mathrm{~mm}$ \\
\hline $\begin{array}{l}\text { Geometry of } \\
\text { source positions } \\
(6 \mathrm{~B})^{\star}\end{array}$ & $\begin{array}{l}\text { Different (in this } \\
\text { case CDP) }\end{array}$ & ABDP & ABDP & CDP & ABDP & ABDP \\
\hline $\begin{array}{l}\text { Dose voxel size } \\
\text { (9) }[\mathrm{cm}]\end{array}$ & $0.1 \times 0.1 \times 0.1$ & $0.05 \times 0.05 \times 0.1$ & $0.25 \times 0.25 \times 0.1$ & $0.05 \times 0.05 \times 1$ & $0.1 \times 0.1 \times 0.1$ & $0.1 \times 0.1 \times 0.1$ \\
\hline $\begin{array}{l}\text { "Planning source } \\
\text { strength" (10) }\end{array}$ & Nominal & Nominal & Nominal & Actual & Actual & Actual \\
\hline
\end{tabular}

${ }^{*} A B D P$ - anatomy-based dwell position, $C D P$ - cylindrical dwell position

The clinics had different rules and practices regarding how to place the catheters. Two of the clinics (B and C) stated that the catheters should pass through the prostate capsule (CTV) in at least one image slice, and two clinics (A and D) indicated that all catheters should go through PTV in at least one image slice. Also, most of the clinics stated that a catheter should have at least a $5 \mathrm{~mm}$ distance to the urethra, whereas two clinics (C and D) confirmed that a catheter could be as close as $3 \mathrm{~mm}$ to the urethra, but the nearest dwell position should not be closer than $5 \mathrm{~mm}$. Only one clinic (A) allowed catheters above the urethra (high in the middle column in the template), which was one of the clinics with the best target coverage
(Table 6). The distance between catheters should be larger than $5 \mathrm{~mm}$ (A, B, and C), but preferably not more than $7 \mathrm{~mm}$ apart (C). One clinic (F) had a template with possible catheter positions $2.5 \mathrm{~mm}$ apart instead of the more common distance of $5 \mathrm{~mm}$.

The clinics' methods for drawing the urethra were not explicitly questioned, but two clinics stated that their routine was different from the drawing included in the audit case. In the audit, the urethra was presented with a diameter of $5 \mathrm{~mm}$ and was drawn as a Foley catheter inside the urethra. One clinic was using a diameter of $6 \mathrm{~mm}$, and one clinic was using contrast in the urethra, and could thereby contour the urethra instead of the catheter.

Table 6. Dosimetric indices extracted from the dose volume histogram for clinical target volume and organs at risk for the audit case. The six clinics are denoted from $A$ to $E$. The values in parenthesis are for the complementary treatment plans made by the A and B clinics. The uncertainty for the dosimetric indices is less than $5 \%$

\begin{tabular}{|c|c|c|c|c|c|c|}
\hline & $\mathrm{A}$ & $\mathrm{B} 1$ & $\mathrm{~B} 2$ & $\mathrm{C}$ & $\mathrm{D}$ & $\mathrm{E}$ \\
\hline$D_{90 \%}^{\text {CTV }}(G y)$ & $10.8(10.8)$ & $10.5(10.4)$ & 11.0 (11.1) & 11.0 & 10.7 & 11.0 \\
\hline $\mathrm{D}_{95 \%}^{\mathrm{CTV}}(\mathrm{Gy})$ & $10.5(10.5)$ & $10.2(10.2)$ & $10.7(10.8)$ & 10.7 & 10.2 & 10.8 \\
\hline $\mathrm{V}_{100 \%}^{\mathrm{CTV}}(\%)$ & 99.9 (100) & $96.5(97.0)$ & $98.5(99.0)$ & 98.7 & 96.0 & 99.9 \\
\hline $\mathrm{V}_{150 \%}^{\mathrm{CTV}}(\%)$ & $17.8(20.6)$ & $24.0(21.8)$ & $27.7(29.9)$ & 32.0 & 22.5 & 22.4 \\
\hline $\mathrm{V}_{200 \%}^{\mathrm{CTV}}(\%)$ & $5.3(5.9)$ & $8.9(7.3)$ & $8.2(9.0)$ & 9.9 & 6.4 & 7.0 \\
\hline$D_{2 c c}^{\text {rectum }}$ (Gy) & $4.7(4.2)$ & $4.5(3.8)$ & $4.8(4.0)$ & 4.9 & 4.4 & 4.7 \\
\hline $\mathrm{D}_{0.1 \mathrm{ccc}}^{\text {urethra }}$ (Gy) & $10.6(10.9)$ & $10.3(10.2)$ & $10.8(10.9)$ & 10.8 & 10.5 & 11.1 \\
\hline $\mathrm{D}_{10 \%}^{\text {urethra }}$ (Gy) & $10.7(10.9)$ & $10.3(10.2)$ & $10.9(10.9)$ & 10.9 & 10.6 & 11.2 \\
\hline $\mathrm{D}_{30 \%}^{\text {urethra }}$ (Gy) & $10.5(10.7)$ & $10.2(10.1)$ & $10.7(10.8)$ & 10.7 & 10.5 & 10.9 \\
\hline
\end{tabular}



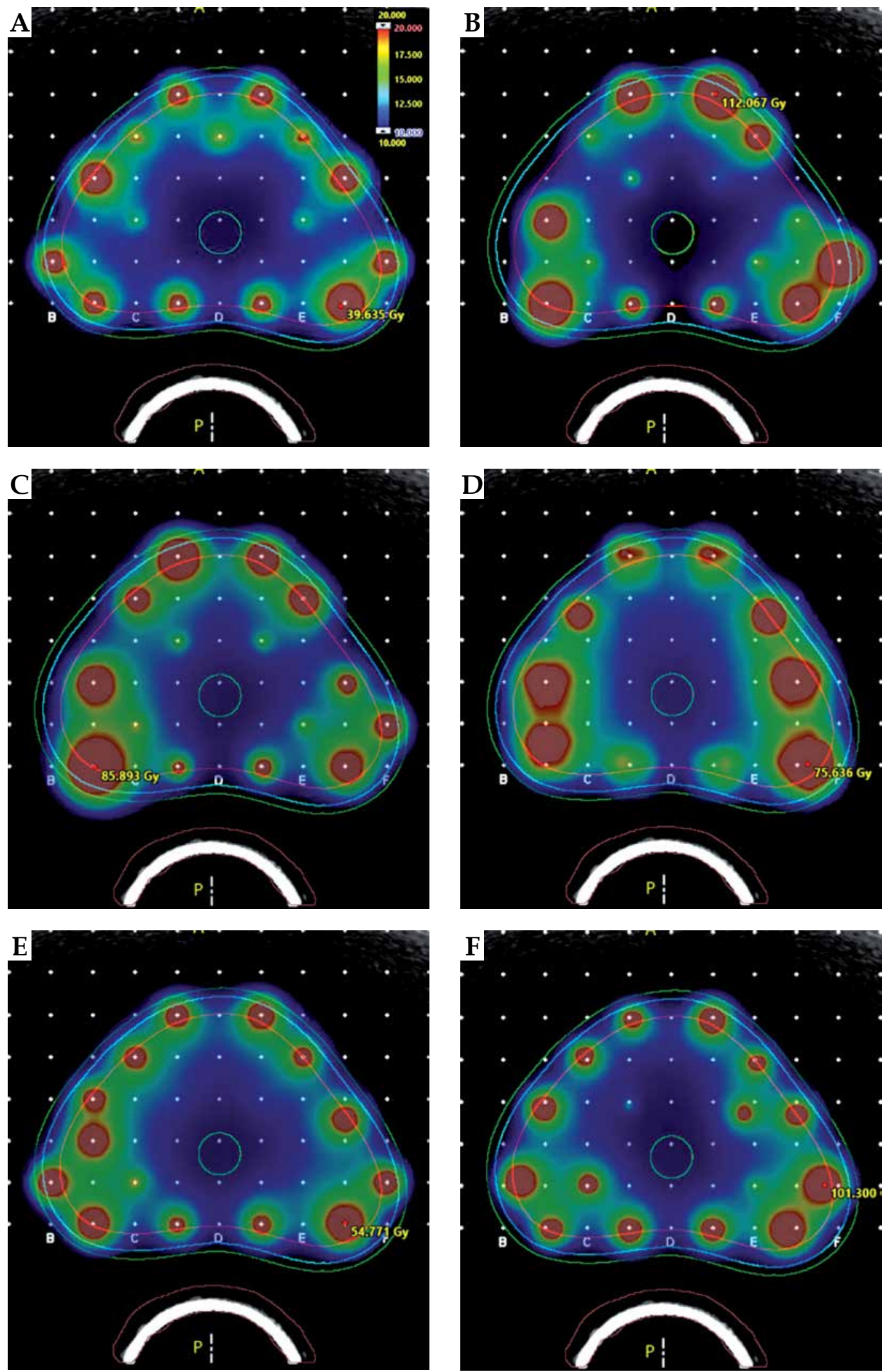

Fig. 3. One slice from the treatment plan from the six clinics, denoted as letters from A to E, showing the dose distribution in color wash. The regions with color receive $10 \mathrm{~Gy}$ or more, the red regions receive $20 \mathrm{~Gy}$ or more; A) A with the color bar, B) B1, C) B2, D) C, E) D, F) E. The contours represent CTV (red), PTV with $2 \mathrm{~mm}$ margin (light blue), PTV with $3 \mathrm{~mm}$ margin (dark green), urethra (light green) rectum (brown). The white dots and letters are from the ultrasound, for visualizing the templates holes and the index names of holes 


\section{Treatment planning}

The three-dimensional dose distributions from the treatment plans (i.e., the DICOM-RT part) were imported to BrachyVision for viewing and extraction of dose volume histogram (DVH) information. All treatment plans, except one, were successfully imported to BrachyVision v.13.6. A central slice of the treatment plan for all participating clinics is shown in Figure 3 with dose color wash, where the colored regions received $10 \mathrm{~Gy}$ or more.

\section{Dosimetric indices}

The dosimetric indices were extracted and calculated for target volumes with the urethra excluded. Table 6 lists the DIs for CTV and OARs. In international guidelines and recommendations, $\mathrm{D}_{90 \%}$ is chosen as the prescription dose. If all the clinics were prescribing the dose to CTV, prescription doses would range from 10.5 Gy to 11.0 Gy, which in $2 \mathrm{~Gy}$, equivalent doses were from $28.4 \mathrm{~Gy}$ to $30.8 \mathrm{~Gy}$. If the volume that the different clinics were using as a target (PTV with margins as described in Table 5) was applied, the prescription dose ranged from 10.0 Gy to $11.1 \mathrm{~Gy}$, and corresponded to $\mathrm{EQD}_{2}$ from $26.0 \mathrm{~Gy}$ to 31.3 Gy. Including the EBRT part of the treatment of $50 \mathrm{~Gy}$ and two fractions of $\mathrm{BT}$, equal to an $\mathrm{EQD}_{2}$ ranging from
$102 \mathrm{~Gy}$ to $112.6 \mathrm{~Gy}$. The recommended OARs constraints from GEC/ESTRO (Table 2) were met for all the clinics, except for the $\mathrm{D}_{30 \%}^{\text {urethra }}$ which only one treatment plan fulfills (B1).

The DIs for the second prostate case that two clinics made treatment plans for are included in Table 6. The results were consistent with those for the smaller prostate. The treatment plans calculated with different dose voxel size were for $\mathrm{D}_{2 \mathrm{cc}}^{\text {rectum }}$ and $\mathrm{D}_{0.1 \mathrm{cc}}^{\text {urethra }}$, giving the same values. $\mathrm{D}_{90 \%}{ }_{\mathrm{CTV}}$ obtained the same value. However, for $\mathrm{V}_{100 \%}{ }_{\mathrm{CTV}}, \mathrm{V}_{150 \%}{ }_{\mathrm{CTV}}$, and $\mathrm{V}_{200 \%}{ }_{\mathrm{CTV}}$, there were small changes in values: the changes were greater for the audit case than for the additional case.

DNR, COIN, and LCVaR values are presented in Table 7. DNR for the treatment plans differed at maximum for CTV with 0.14, which was due to the difference in size of the high-dose regions (Table $6, \mathrm{~V}_{200 \%}{ }^{\mathrm{CTV}}$ ). For COIN, the range for PTV was 0.06, and for CTV, it was 0.07. A COIN value above 0.64 was the preferred target according to Baltas et al. [22] and for PTV, the audit COIN value was at least 0.70 . For CTV, the COIN values were under 0.64 , which in this case depended on irradiation of tissue outside the CTV, as the clinics were aiming to apply doses to larger PTV. For an $\alpha$ of 5\%, LCVaR differed by 1.15 Gy and for an $\alpha$ of $1 \%, \mathrm{LCVaR}$ varied by $1.89 \mathrm{~Gy}$.

Table 7. The calculated dosimetric indices for the target volumes; dose non-homogeneity ratio (DNR), conformal index (COIN), and mean dose to the coldest volume (LCVaR). The clinics are denoted from A to E. Clinic B changed methods during the audit and provided two answers: B1, the old method and B2, the new method

\begin{tabular}{lccccccccc} 
& \multicolumn{3}{c}{ DNR } & \multicolumn{3}{c}{ COIN } & \multicolumn{2}{c}{ LCVaR } \\
\cline { 2 - 10 } & PTV $_{2 \mathrm{~mm}}$ & PTV $_{3 \mathrm{~mm}}$ & CTV & PTV $_{2 \mathrm{~mm}}$ & PTV $_{3 \mathrm{~mm}}$ & CTV & CTV $\alpha=5 \%$ & CTV $\alpha=1 \%$ \\
\hline A & 0.21 & 0.21 & 0.18 & 0.74 & 0.80 & 0.55 & 10.34 & 10.07 \\
\hline B1 & 0.27 & 0.27 & 0.25 & 0.75 & 0.78 & 0.59 & 9.40 & 8.65 \\
\hline B2 & 0.30 & 0.29 & 0.28 & 0.76 & 0.82 & 0.57 & 10.17 & 9.35 \\
\hline C & 0.33 & 0.31 & 0.32 & 0.70 & 0.78 & 0.52 & 10.21 & 9.41 \\
\hline D & 0.25 & 0.24 & 0.23 & 0.75 & 0.83 & 0.56 & 9.35 & 8.33 \\
\hline E & 0.24 & 0.23 & 0.22 & 0.74 & 0.80 & 0.55 & 10.50 & 10.22
\end{tabular}

PTV - planning target volume, CTV - clinical target volume

Table 8. Dwell time data from the report of treatment plans, derived from the individual clinics' (denoted from A to E) treatment planning systems. The times are recalculated to nominal source strength of $40.7 \mathrm{mGy} / \mathrm{h}$ and are listed in seconds. Some clinics have dwell positions with $0 \mathrm{~s}$ in between non-zero dwell positions, the positions with $0 \mathrm{~s}$ are not included in the analysis. However, for clarity, the $0 \mathrm{~s}$ positions are included in parenthesis in the Table (including 0 positions)

\begin{tabular}{|c|c|c|c|c|c|c|}
\hline Parameter & $A$ & B1 & B2 & C & $\mathrm{D}$ & $E$ \\
\hline Mean & 2.55 & 3.03 & 2.99 & 3.29 & 2.39 & 1.15 \\
\hline Median & 2.2 & 1.9 & 2.4 & 3.0 & 2.2 & 1.0 \\
\hline Max. & 9.9 & 10.8 & 10.4 & 10.0 & 5.3 & 4.4 \\
\hline Min. & 0.4 & 0.3 & 0.3 & 0.7 & 0.6 & 0.03 \\
\hline SD & 1.75 & 2.86 & 2.58 & 2.02 & 1.14 & 0.7 \\
\hline $\begin{array}{l}\text { \#Positions } \\
\text { (incl. } 0 \text { positions) }\end{array}$ & $\begin{array}{c}101 \\
(101)\end{array}$ & $\begin{array}{c}76 \\
(76)\end{array}$ & $\begin{array}{l}83 \\
(83) \\
\end{array}$ & $\begin{array}{c}78 \\
(112)\end{array}$ & $\begin{array}{c}99 \\
(107)\end{array}$ & $\begin{array}{r}219 \\
(219)\end{array}$ \\
\hline Total time & 257.4 & 230.1 & 248 & 256.8 & 236.3 & 252.8 \\
\hline TRAK (mGy at $1 \mathrm{~m}$ ) & 2.91 & 2.60 & 2.81 & 2.90 & 2.67 & $2.9^{*}$ \\
\hline
\end{tabular}

*Only 2 decimals from the TPS was obtained, SD - standard deviation, TRAK - total reference air kerma 


\section{Analysis of the treatment plan reports}

Dwell time data are shown in Table 8. One clinic (E) used a dwell step size of $2.5 \mathrm{~mm}$ and the others, $5 \mathrm{~mm}$, which was why the maximum dwell time and the number of dwell positions for clinic E differed with a factor of approximately 0.4 and 2.5 , respectively, compared to the other clinics. The minimum dwell times did not consider positions with zero dwell times; the treatment plans from two of the clinics (C and D) included some zero dwell times. Two examples of the distribution of dwell times can be seen in Figure 4.

The number of catheters and the size of the relative volume of the CTV that received at least $200 \%$ of the prescription dose had the strongest dependence of parameters and variables (Figure 5); the more catheters, the smaller the relative volume of $200 \%$ dose in CTV. The correlation between the relative volume of CTV that received at least $100 \%$ of the dose and the dose to urethra was not strong, with an $R^{2}$ value of 0.55 (Figure 6A). Moreover, there seem to be no correlation between the number of catheters and the dose to the urethra (Figure 6B), which showed a low $R^{2}$ value.

A

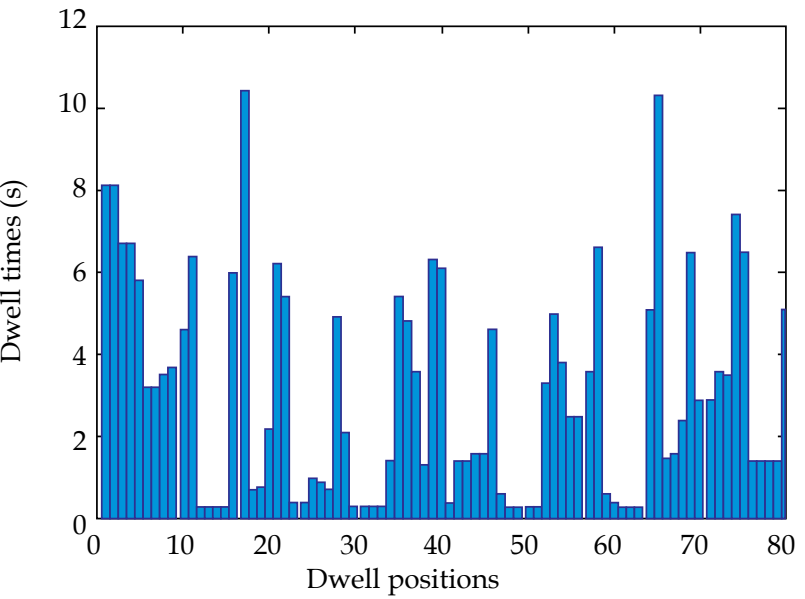

C

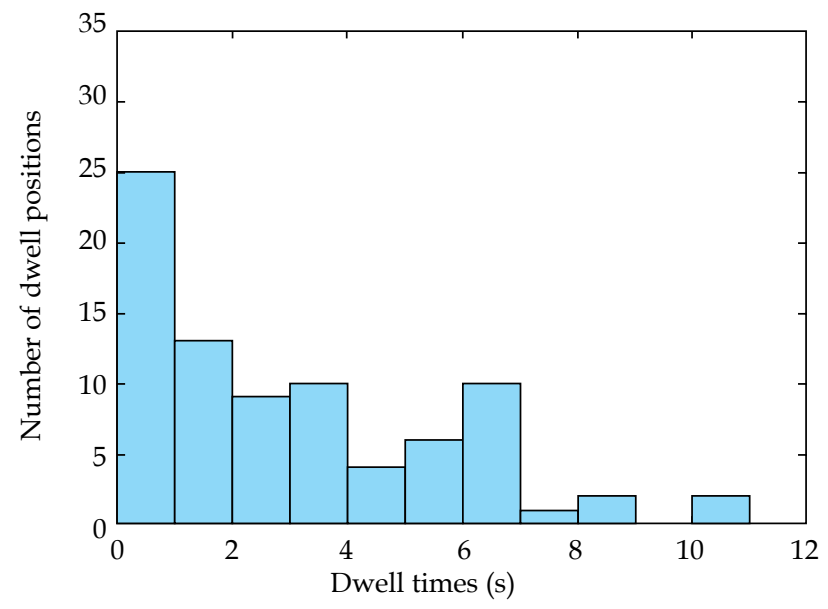

\section{Discussion}

The audit was constructed to highlight different clinical routines for treatment planning, regarding technical and dosimetric aspects. As the clinics were using different CTV to PTV margins, the prescription dose was prescribed for different volumes, which complicated even more the comparison. The comparison showed the differences in dosage a patient would have received, if he had been treated at different clinics, under the assumption that all the clinics would contour the prostate (CTV), urethra, and rectum equally.

The prescribed dose to the prostate according to the international recommendations is based on D90\% value, which in our audit was one parameter used to compare the treatment plans. According to answers for questions provided in the questionnaire, the planning aims were to give 10.0 Gy to $95-100 \%$ of PTV. The Swedish National Care Programme does not state to which volume (CTV or PTV) the prescribed dose should be given. As the proposed dose constraints for OARs were fulfilled (except for $\mathrm{D}_{30 \%}^{\text {urethra }}$ ), it could be favorable to give a higher dose to the target volume, as the prostate is not a functional

B

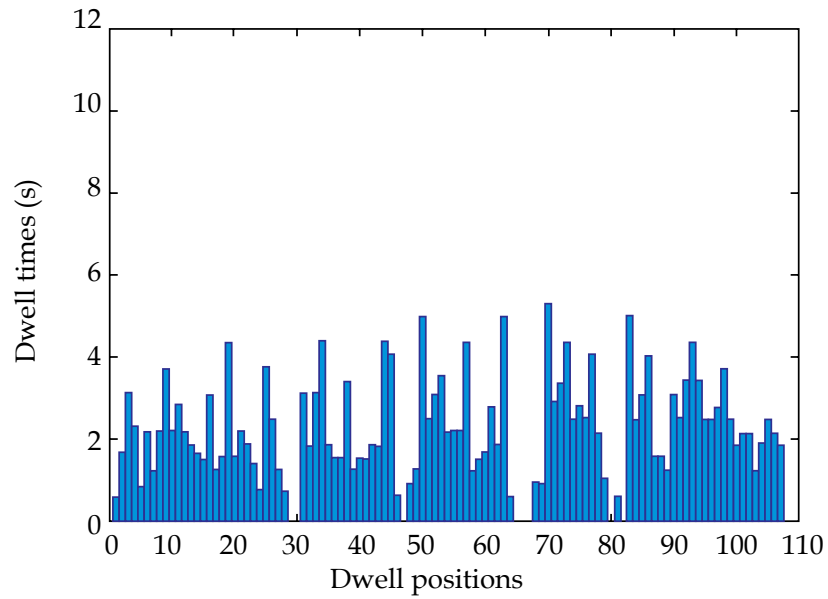

D

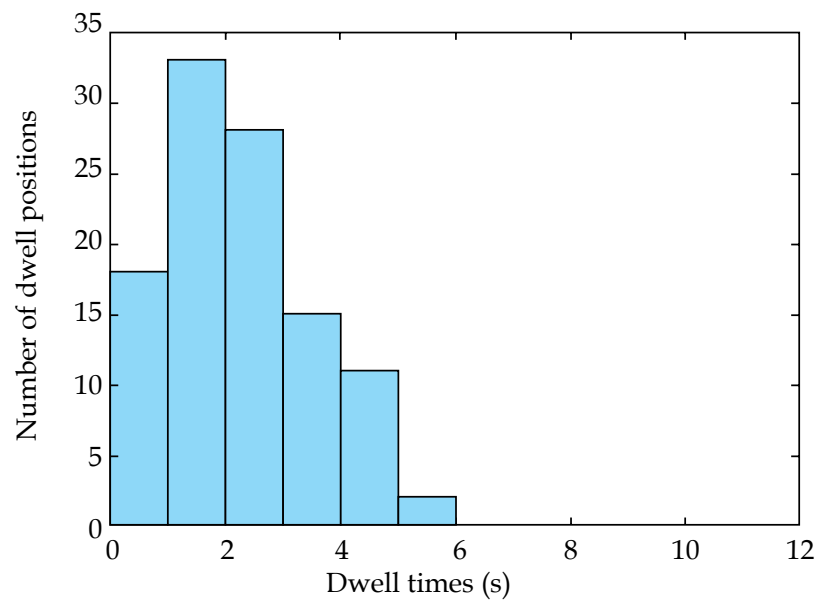

Fig. 4. The dwell times for the catheters one after another for two of the clinics, denoted as B2 (the clinic has made two treatment plans) and D, A) B2 and B) D. Histogram for distribution of dwell times for clinic C) B2 and D) D 


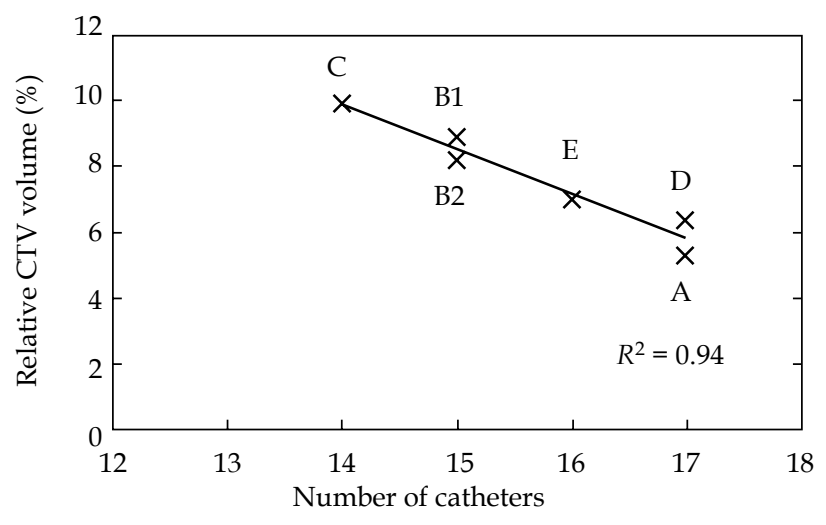

Fig. 5. The relative CTV volume that receives more than $200 \%$ of the dose as a function of number of catheters, yielding the equation $\mathrm{V}(200 \%)(\mathrm{CTV})=-1.359 \mathrm{x}+28.9$. The five clinics with data are named from A to E, with clinic B having two treatment plans due to changing methods during the time of the audit. $R^{2}$ is the coefficient of determination

organ. The proposed dose constraint for $\mathrm{D}_{30 \%}^{\text {urethra }}$ did not seem to be a constraint, which the Swedish clinics have adopted, as only one treatment plan in the audit was fulfilling that criterion. It could be that the clinics are not willing to give less than the prescription dose to the urethra as a caution against underdose of the target volume. The dose constraints for the urethra for the clinics differed with up to $2 \mathrm{~Gy}$, and none of the clinics had any constraint for $\mathrm{D}_{30 \%}$ urethra. As for rectum, it differed with 2 Gy. The treatment plans did not reflect these differences in planning aims; urethra differed with less than $1 \mathrm{~Gy}$ for the DIs used in the audit and rectum with $0.5 \mathrm{~Gy}$. A higher urethral dose could increase the number of higher incidence of urethral strictures; however, the loss of dose to the target near the urethra could compromise local control.

The DIs uncertainty for the treatment plans depended on the voxel size used for the final dose calculation. A larger dose voxel size generated lower maximum dos-

A

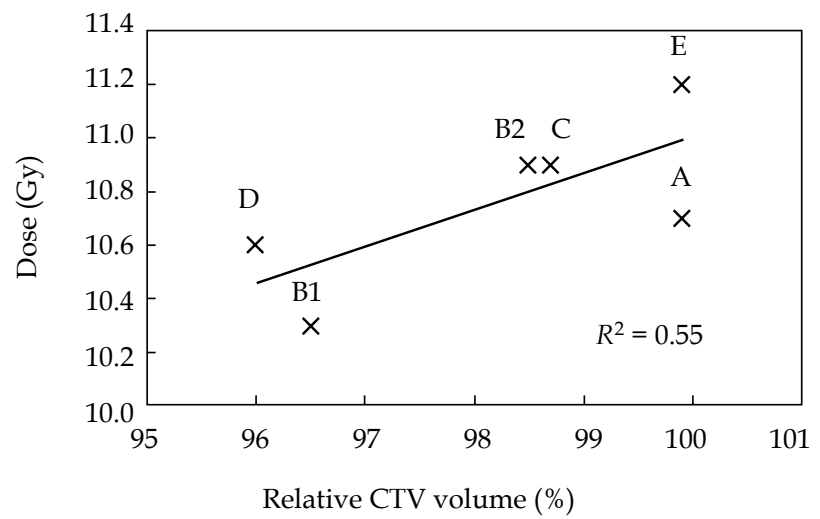

es, as the regions near dwell positions were averaged. The values of the DIs used in our audit were most likely not affected by the dose voxel size, as the maximum doses were not included and the DIs for OARs were not close to the maximum doses, such doses were found near the dwell positions. However, for some structures and clinics, the number of dose points were far less than the number of points recommended by Van der Meer et al. [28] to achieve a confidence interval of $95 \%$.

The treatment plans varied in the number and geometry of the catheters. Some clinics had only straight catheters (parallel to the US probe) constrained to the template grid; others applied catheters in between the template grid or skew catheters that were not parallel to the US probe. This is seen in Figure 3, where high-dose regions are not always centered around the white dots representing the holes in a template. The effect of such strategies for placing catheters were not considered in the evaluation of the results; although it could be a way of getting more dwell positions inside the PTV, and in that way achieving a better target coverage with less irradiation of the normal tissue surrounding the target. It is an interesting observation, as this could be a strategy in some clinics to try to place the catheters skewed to get a better target coverage. The placement of dwell positions could also affect the possible number of dwell positions inside the target volume. The more dwell positions, the more degrees of freedom in the dose optimization. The rules for catheter positioning also affect the result of the $\mathrm{D}_{90 \%}$ as, for example, the possibility to position catheters above the urethra (high in the middle in the template), which results in the best target coverage. The possibility to place catheters near the urethra and outside PTV could also help to improve the target coverage. The dose constraints for OARs also affected the target coverage, as the clinic that changed the dose constraints during the audit improved the $D_{90 \%}$. It could also be seen that the clinics with the least restrictive dose constraints to OARs were the clinics with the highest LCVaR, i.e., having the smallest number of cold spots.

\section{B}

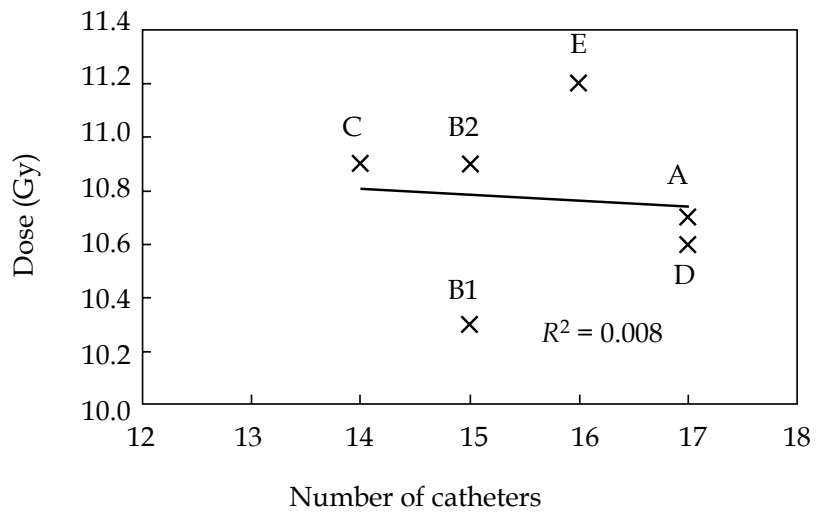

Fig. 6. The dose to the $10 \%$ of urethra that receives the highest dose as a function of A) the CTV coverage (the relative volume of CTV that receives $100 \%$ of the dose) and B) the number of catheters. The functions for the linear dependence are $\mathbf{A}) \mathrm{D}(10 \%)$ (urethra) $=0.1366 x-2.66$ and B) $\mathrm{D}(10 \%)$ (urethra) $=-0.023 x+11.1$. The five clinics with the data are named from $\mathrm{A}$ to $\mathrm{E}$, with clinic B having two treatment plans due to changing methods during the time of the audit; the old method is named B1 and the new technique is named B2. $R^{2}$ is the coefficient of determination 
The results seem to indicate that it is good to have as many catheters as possible to get as small high-dose ( $\geq 200 \%$ ) volume as possible (Figure 5). However, too many catheters can increase the risk of urinary toxicity [29]. A number of studies have looked at the optimal number of catheters $[30,31,32,33]$. The ABS recommends the use of at least 14 catheters [18], while the GEC/ ESTRO suggests that the catheters should be placed not further apart than $1 \mathrm{~cm}$ to achieve a homogenous dose distribution. Charra-Brunaud et al. [30] did not observe any statistically significant difference in the dose distribution between groups of 15 to 21 catheters. In our audit, it could be noted that the lowest DNRs were for the clinics with the least number of catheters. Baltas et al. [34] and Mavroidis et al. [35] indicated that if there is no information about the necessity of a hot spot, then hot spots should be avoided. The studies of Baltas and Mavroidis are in the field of monotherapy, where the entire dose to the target is given by HDR-BT. It can also be mentioned that any relationship between toxicity and the volume of hot spots in the normal tissue or the target volume has not been well established [36].

There are no recommendations for acceptable values of DNR and COIN; however, these parameters are frequently used for comparison of treatment plans. In our audit, the DNR for the treatment plans were in the same range as in published results [24], and the homogeneity of treatment plans was good with one treatment plan (A), considered as the most homogenous treatment plan. COIN values for PTV are all in the upper part of the published data [14]. Here, the COIN values for the CTV were all in the lower part of published data, due to the irradiation of tissue outside CTV, since the clinics were treating the PTV. Both DNR and COIN indicated that there was no significant difference in the treatment plans. COIN can alternatively be calculated with an additional parameter with organs at risk taken into account [22]. This was not used in our audit, as the urethra was situated inside the target volume and therefore given the prescribed dose. The LCVaR values for an $\alpha$ of $5 \%$ were all, except two, above the prescription dose, and the values for two treatment plans below the prescription dose were at most $0.7 \mathrm{~Gy}$ under. In LCVaR for an $\alpha$ of $1 \%$, two of the clinics still had values above the prescription dose, which also can be seen in Table 6, as these clinics present $\mathrm{V}_{100 \%}{ }_{\mathrm{CTV}}$ values of $99.9 \%$. The clinics with the lowest LCVaR for an $\alpha$ of $1 \%$ were over $8 \mathrm{~Gy}$, which would give a treatment dose of approximately 85 Gy EQD 2 . The published planning aims according to the GEC/ESTRO recommendations [17] specify doses of approximately $70 \mathrm{~Gy} \mathrm{EQD}_{2}$ to $105 \mathrm{~Gy}$ $\mathrm{EQD}_{2}$. The Swedish equivalent treatment regime with only EBRT is in concordance with the National Care Programme of $78 \mathrm{~Gy}$ in $39 \mathrm{fx}$.

The total treatment time and the TRAK were both within approximately $10 \%$ for all the treatment plans, showing resemblances among them. The mean times and the maximum times were also within the same size for three clinics A, B, and C, with less than $1 \mathrm{~s}$ difference. Two clinics (D and E) deviated from the other clinics, for which one of them (E) could be explained by another dwell step size and vendor. Multiplied by a factor of two, the mean and maximum time would be $1.3 \mathrm{~s}$ respective $8.8 \mathrm{~s}$ for clinic $\mathrm{E}$, which still were smaller than clinic A, $B$, and C. Different vendors have different inverse optimization algorithms, which could explain the deviation in the mean and maximum dwell times. Clinic D was the only clinic that was not using any inverse planning; this could be the reason for a low maximum time and a low standard deviation. This is shown in Figure 4, where the dwell times vary more for clinic B2, which used inverse treatment planning, than for clinic $\mathrm{D}$, where manual and graphical treatment planning were used. The histogram for clinic D was more centered around the low dwell times (Figure 6C and D). The different minimum dwell times could be due to different optimization techniques or different precautions of the transit dose [37].

A limitation of our audit is that it only consists of one prostate case that all clinics participated in, and an additional prostate case for two clinics only. The treatment planning was assumed to be planned by one person and should represent the treatment planning process of the clinics, although the treatment planning was carried out under other circumstances, which differ from clinical practice. The treatment planning time is, for example, not a limiting factor. A complicating factor for the audit is that the handling of DICOM-RT files were not consistent between different TPSs. This must first be resolved in order to be able to perform an audit, where all different clinics with different TPSs could participate.

\section{Conclusions}

The dose constraints for the clinics participating in the audit are showing a larger variation between the clinics than visible in the treatment plans compared. The largest variation in the treatment plans are for urethra and the sizes of hot spots in CTV. A higher dose to the urethra could provide a higher incidence of complications to the patient. The consequences of the sizes of hot spots in the prostate are not well established.

All the treatment plans in the audit follow the $\mathrm{Na}$ tional Care Programme in applying $102 \mathrm{~Gy} \mathrm{EQD}_{2}$ to the prostate, even though, the prescription doses for some of the treatment plans are exceeding the dose by up to $10 \mathrm{~Gy} \mathrm{EQD}_{2}$. The recommended prescription doses in Sweden are in the upper part of the fractionation schemes in the GEC/ESTRO recommendations [17]. The treatment plans are also fulfilling the proposed constraints to OARs in the GEC/ESTRO guidelines, except for $\mathrm{D}_{30 \%}^{\text {urethra }}$, which only one treatment plan was fulfilling. The results have been shared with the clinics that participated in the audit.

\section{Acknowledgements}

The contribution from the medical physicists performing the treatment planning and answering the questionnaire is greatly acknowledged; thank you for your time. This work was supported by grants from Radiumhemmets forskningsfonder (Stockholm, Sweden, grant No. 161042) and by the Swedish Cancer Society, grants No. CAN 2018/622 and CAN 2017/1029. 


\section{Disclosure}

The authors report no conflict of interest.

\section{References}

1. Borghede G, Hedelin H, Holmäng $S$ et al. Irradiation of localized prostatic carcinoma with a combination of high dose rate iridium-192 brachytherapy and external beam radiotherapy with three target definitions and dose levels inside the prostate gland. Radiother Oncol 1997; 44: 245-250.

2. Åström L, Pedersen D, Mercke C et al. Long-term outcome of high dose rate brachytherapy in radiotherapy of localised prostate cancer. Radiother Oncol 2005; 74: 157-161.

3. Kälkner KM, Wahlgren T, Ryberg M et al. Clinical outcome in patients with prostate cancer treated with external beam radiotherapy and high dose-rate iridium 192 brachytherapy boost: A 6-year follow-up. Acta Oncol 2007; 46: 909-917.

4. Åström L, Grusell E, Sandin F et al. Two decades of high dose rate brachytherapy with external beam radiotherapy for prostate cancer. Radiother Oncol 2018; 127: 81-87.

5. Regionalt cancercentrum, National care program prostate cancer v5.0. 2020. 2020-03-03.

6. Borghede G, Hedelin H, Holmäng S et al. Combined treatment with temporary short-term high dose rate Iridium-192 brachytherapy and external beam radiotherapy for irradiation of localized prostatic carcinoma. Radiother Oncol 1997; 44: 237-244.

7. Lennernäs B, Majumder K, Damber JE et al. Radical prostatectomy versus high-dose irradiation in localized/locally advanced prostate cancer: A Swedish multicenter randomized trial with patient-reported outcomes. Acta Oncol 2015; 54: 875-881.

8. Palmer A, Bradley D, Nisbet A. Physics-aspects of dose accuracy in high dose rate (HDR) brachytherapy: source dosimetry, treatment planning, equipment performance and in vivo verification techniques. J Contemp Brachytherapy 2012; 4: 81-91.

9. Deist TM, Gorissen BL. High-dose-rate prostate brachytherapy inverse planning on dose-volume criteria by simulated annealing. Phys Med Biol 2016; 61: 1155-1170.

10. De Boeck L, Beliën J, Egyed W. Dose optimization in highdose-rate brachytherapy: A literature review of quantitative models from 1990 to 2010. Oper Res Health Care 2014; 3: 80-90.

11. Smith RL, Panettieri V, Lancaster C et al. The influence of the dwell time deviation constraint (DTDC) parameter on dosimetry with IPSA optimisation for HDR prostate brachytherapy. Australas Phys Eng S 2015; 38: 55-61.

12. Poder J, Whitaker M. Robustness of IPSA optimized highdose-rate prostate brachytherapy treatment plans to catheter displacements. J Contemp Brachytherapy 2016; 8: 201-207.

13. Kolkman-Deurloo IKK, Deleye XGJ, Jansen PP et al. Anatomy based inverse planning in HDR prostate brachytherapy. Radiother Oncol 2004; 73: 73-77.

14. Jamema S, Saju S, Shetty U et al. Dosimetric comparison of inverse optimization with geometric optimization in combination with graphical optimization for HDR prostate implants. Med Phys 2006; 31: 89-94.

15. Panettieri V, Smith RL, Mason NJ et al. Comparison of IPSA and HIPO inverse planning optimization algorithms for prostate HDR brachytherapy. J Appl Clin Med Phys 2014; 15: 5055.

16. Dinkla AM, van der Laarse R, Kaljouw E et al. A comparison of inverse optimization algorithms for HDR/PDR prostate brachytherapy treatment planning. Brachytherapy 2015; 14 279-288.

17. Hoskin PJ, Colombo A, Henry A et al. GEC/ESTRO recommendations on high dose rate afterloading brachytherapy for localised prostate cancer: An update. Radiother Oncol 2013; 107: 325-332.

18. Yamada Y, Rogers L, Demanes DJ et al. American Brachytherapy Society consensus guidelines for high-dose-rate prostate brachytherapy. Brachytherapy 2012; 11: 20-32.

19. Clark CH, Jornet N, Muren LP. The role of dosimetry audit in achieving high quality radiotherapy. Phys Imag Radiat Oncol 2018; 5: 85-87.

20. Joiner MC, Van der Kogel A. Basic clinical radiobiology. $5^{\text {th }}$ ed. CRC Press 2018; 98-110.

21. Saw CB, Suntharalingam N. Quantitative assessment of interstitial implants. Int J Radiat Oncol Biol Phys 1991; 20: 135-139.

22. Baltas D, Kolotas C, Germani $\mathrm{K}$ et al. A conformal index (COIN) to evaluate implant quality and dose specification in brachytherapy. Int J Radiat Oncol Biol Phys 1998; 40: 515-524.

23. Morén B. Mathematical modelling of dose planning in high dose-rate brachytherapy. Linköping studies in science and technology licentiate thesis. Linköping University Electronic Press, Linköping 2019; 63.

24. Yoshioka Y, Nishimura T, Kamata M et al. Evaluation of anatomy-based dwell position and inverse optimization in high-dose-rate brachytherapy of prostate cancer: a dosimetric comparison to a conventional cylindrical dwell position, geometric optimization, and dose-point optimization. Radiother Oncol 2005; 75: 311-317.

25. Das RK. ICRU 58 (Dose and Volume Specification for Reporting Interstitial Therapy), by International Commission on Radiation Units and Measurements, 1998: 2.

26. DeWerd LA, Ibbott GS, Meigooni AS et al. A dosimetric uncertainty analysis for photon-emitting brachytherapy sources: Report of AAPM Task Group No. 138 and GEC-ESTRO. Med Phys 2011; 38: 782-801.

27. Kirisits C, Rivard MJ, Baltas D et al. Review of clinical brachytherapy uncertainties: Analysis guidelines of GECESTRO and the AAPM. Radiother Oncol 2014; 110: 199-212.

28. van der Meer MC, Bosman PAN, Pieters BR et al. Sensitivity of dose-volume indices to computation settings in high-doserate prostate brachytherapy treatment plan evaluation. J Appl Clin Med Phys 2019; 20: 66-74.

29. Vargas C, Ghilezan M, Hollander M et al. A new model using number of needles and androgen deprivation to predict chronic urinary toxicity for high or low dose rate prostate brachytherapy. J Urol 2005; 174: 882-887.

30. Charra-Brunaud C, Hsu ICJ, Weinberg V et al. Analysis of interaction between number of implant catheters and dose-volume histograms in prostate high-dose-rate brachytherapy using computer model. Int J Radiat Oncol Biol Phys 2003; 56: 586-591.

31. Poulin E, Fekete CC, Létourneau M et al. Adaptation of the CVT algorithm for catheter optimization in high dose rate brachytherapy. Med Phys 2013; 40: 111724.

32. Poulin E, Varfalvy N, Aubin S et al. Comparison of dose and catheter optimization algorithms in prostate high-dose-rate brachytherapy. Brachytherapy 2016; 15: 102-111.

33. Sadowski KL, Meer MCvd, Luong NH et al. Exploring tradeoffs between target coverage, healthy tissue sparing, and the placement of catheters in HDR brachytherapy for prostate cancer using a novel multi-objective model-based mixedinteger evolutionary algorithm. GECCO'17: Proceedings of the Genetic and Evolutionary Computation Conference, July 2017; 1224-1231.

34. Baltas D, Katsilieri Z, Kefala V et al. Influence of modulation restriction in inverse optimization with HIPO of prostate implants on plan quality: analysis using dosimetric and radiobiological indices. Springer Berlin Heidelberg, Berlin, Heidelberg 2009; 283-286. 
35. Mavroidis P, Katsilieri Z, Kefala V et al. Radiobiological evaluation of the influence of dwell time modulation restriction in HIPO optimized HDR prostate brachytherapy implants. J Contemp Brachytherapy 2010; 2: 117-128.

36. Morton GC, Sankreacha R, Halina P et al. A comparison of anatomy-based inverse planning with simulated annealing and graphical optimization for high-dose-rate prostate brachytherapy. Brachytherapy 2008; 7: 12-16.

37. Wong TPY, Fernando W, Johnston PN et al. Transit dose of an Ir-192 high dose rate brachytherapy stepping source. Phys Med Biol 2000; 46: 323-331. 